\title{
Mechanisms controlling the seasonal mixed-layer temperature and salinity of the Indonesian seas
}

\author{
Daria Halkides • Tong Lee • Shinichiro Kida
}

Received: 3 December 2009 /Accepted: 23 December 2010 /Published online: 18 February 2011

(C) The Author(s) 2011. This article is published with open access at Springerlink.com

\begin{abstract}
We examine the seasonal mixed-layer temperature (MLT) and salinity (MLS) budgets in the BandaArafura Seas region (120-138 $\left.\mathrm{E}, 8^{\circ}-3^{\circ} \mathrm{S}\right)$ using an ECCO ocean-state estimation product. MLT in these seas is relatively high during November-May (austral spring through fall) and relatively low during June-September (austral winter and the period associated with the Asian summer monsoon). Surface heat flux makes the largest contribution to the seasonal MLT tendency, with significant reinforcement by subsurface processes, especially turbulent vertical mixing. Temperature declines (the MLT tendency is negative) in May-August when seasonal insolation is smallest and local winds are strong due to the southeast monsoon, which causes surface heat loss and cooling by vertical processes. In particular, Ekman suction induced by local wind stress curl raises the thermocline in the Arafura Sea, bringing cooler subsurface water closer to the base of the mixed layer where it is subsequently incorporated into
\end{abstract}

Responsible Editor: Joachim W. Dippner

D. Halkides $(\bowtie)$

University of California at Los Angeles-Joint Institute For

Research in Earth System Science and Engineering (JIFRESSE),

Los Angeles, CA, USA

e-mail: halkides@jpl.nasa.gov

T. Lee

Jet Propulsion Laboratory,

California Institute of Technology,

Pasadena, CA, USA

S. Kida

Earth Simulator Center,

Japan Agency for Marine-Earth Science and Technology,

Yokohama, Japan the mixed layer through turbulent vertical mixing; this has a cooling effect. The MLT budget also has a small, but nonnegligible, semi-annual component since insolation increases and winds weaken during the spring and fall monsoon transitions near the equator. This causes warming via solar heating, reduced surface heat loss, and weakened turbulent mixing compared to austral winter and, to a lesser extent, compared to austral summer. Seasonal MLS is dominated by ocean processes rather than by local freshwater flux. The contributions by horizontal advection and subsurface processes have comparable magnitudes. The results suggest that ocean dynamics play a significant part in determining both seasonal MLT and MLS in the region, such that coupled model studies of the region should use a full ocean model rather than a slab ocean mixed-layer model.

Keywords Indonesian seas - Mixed layer - Seasonal heat budget $\cdot$ Seasonal salinity budget $\cdot \mathrm{ECCO} \cdot$ Ocean-state estimation

\section{Introduction}

Mixed-layer temperature (MLT) and mixed-layer salinity (MLS) in the Indonesian Seas (Fig. 1) are important to global climate, local weather, and ecology. The global climate is sensitive to small changes in the regional surface temperature due to its modulation of atmospheric deep convection, which drives the Walker circulations over the Pacific and Indian Oceans, and can thus have ramifications for phenomena such as the Asian monsoon, the El NinoSouthern Oscillation, and the Indian Ocean Zonal/Dipole Mode (e.g., Miller et al. 1992; Ashok et al. 2001; Barsugli 
Fig. 1 Geographical map of the Indonesian seas superimposed over ECCO model topography for the region. The black box denotes the Banda-Arafura Seas area $\left(120-138^{\circ} \mathrm{E}, 8-3^{\circ} \mathrm{S}\right)$ over which spatial averages are taken for all time series in this paper

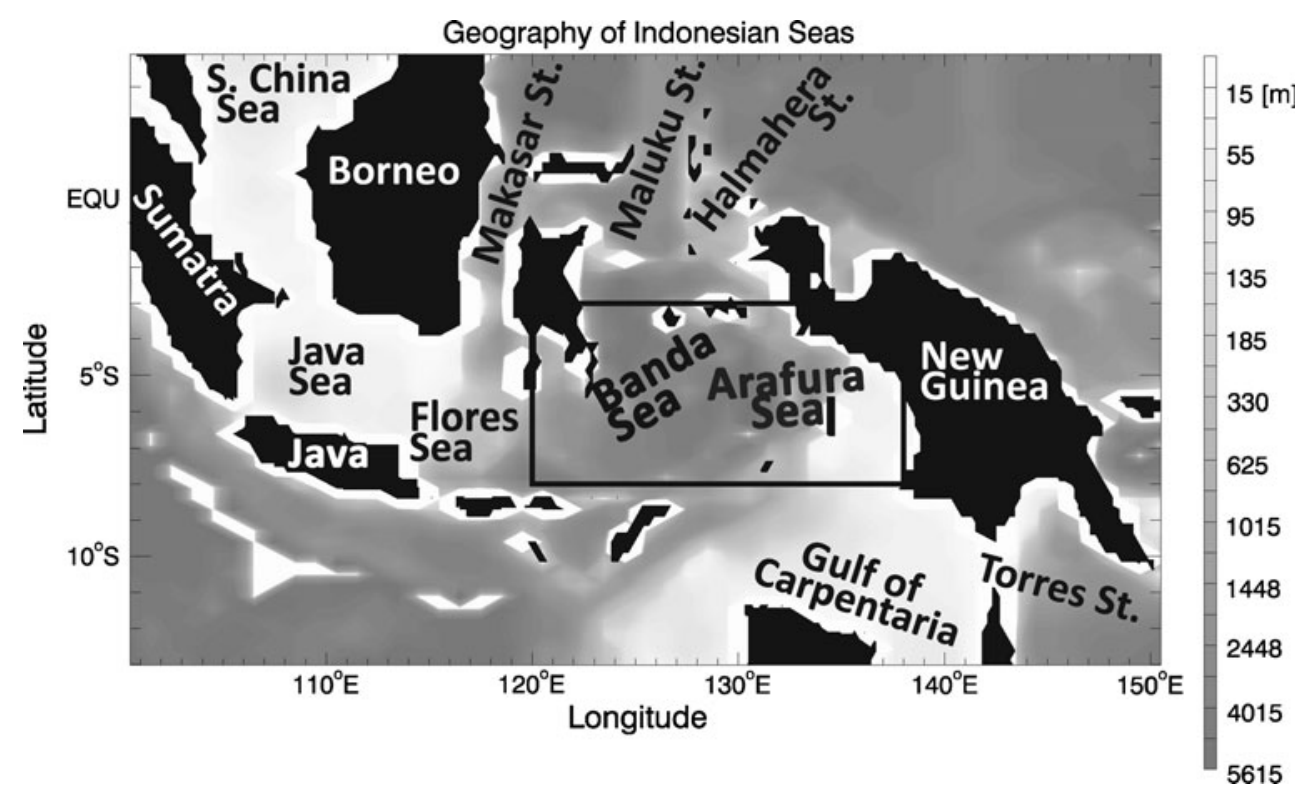

and Sardeshmukh 2002; McBride et al. 2003). Wind-driven Ekman transport out of the Banda Sea may also contribute to sub-annual heat and salinity transports through the exit paths of the Indonesian throughflow (ITF) (e.g., Sprintall and Liu 2005), which impacts the circulation, heat, and salinity balances in the Indian Ocean. Thus, understanding the seasonal variability of MLT and MLS in this region is important for an accurate simulation of both regional and global climate, and it may facilitate studies of ITF water properties and related transports. Unfortunately, the poor simulation of Indonesian Seas surface temperatures in coupled models often causes atmospheric convection/precipitation to be significantly underestimated, propagating errors through the system (e.g., Neale and Slingo 2003).

Some effects of the atmospheric and oceanic circulations on MLT within the Banda-Arafura Seas region have been documented. Winds in this area vary with the monsoon and are predominantly southeasterly (northwesterly) in austral winter (summer). Prior studies show that Ekman upwelling inferred from wind is well correlated with seasonal MLT (e.g., Gordon and Susanto 2001), suggesting potential effects of related subsurface processes on MLT. Additional factors, e.g., seasonal winds, topography, and tides, believed to influence upper ocean mixing, may also regulate seasonal mixed-layer (ML) processes (e.g., Neale and Slingo 2003; Robertson and Ffield 2005; Qu et al. 2005; Koch-Larrouy et al 2008; Kida and Richards 2009). Furthermore, this region may be affected by remote thermocline forcing via waves transmitted from the Indian and Pacific Oceans (e.g., Wijffels and Meyers 2004). MLT and MLS budget analyses can help us to better understand the regional climate and improve model simulations; however, observations for the area are sparse, so such analyses are difficult.
To our knowledge, no complete MLT and MLS budgets of this area have been published previously. In this study, we examine the seasonal MLT and MLS budgets of the Banda-Arafura Seas region using a heat- and saltconserving ocean-state estimate from the Estimating the Circulation and Climate of the Ocean (ECCO) Consortium (see http://ecco-group.org), generated at the National Aeronautics and Space Administration (NASA) Jet Propulsion Laboratory (JPL; http://ecco.jpl.nasa.gov/external). This work can help evaluate coupled climate model simulations and provide context for sparse in situ data for the Banda-Arafura Seas.

In the "ECCO product, validation, and method" section, we describe the ECCO ocean-state estimate from which we derive the MLT and MLS budgets, validate our use of this product, and explain the MLT and MLS equations. In the "Results" section, we present and discuss the seasonal MLT and MLS budgets for the Banda-Arafura region. Concluding remarks are provided in the "Summary and conclusions" section.

\section{ECCO product, validation, and method}

\subsection{ECCO-JPL product description}

The ECCO-JPL system uses a near-global $\left(75^{\circ} \mathrm{S}-75^{\circ} \mathrm{N}\right)$ parallel version of the Massachusetts Institute of Technology (MIT) ocean general circulation model (OGCM), known as MITgem (Marshall et al. 1997). The north and south boundaries are closed. It has a $1^{\circ} \times 0.3^{\circ}$ resolution in the tropics, telescoping to $1^{\circ} \times 1^{\circ}$ in the extra-tropics. There are 46 vertical levels with $10-\mathrm{m}$ resolution in the upper $150 \mathrm{~m}$. The model also uses the Gent-McWilliams (GM) 
(Gent and McWilliams 1990) and K-Profile Parameterization (KPP) mixing (Large et al. 1994) schemes. The detailed configuration is described by Lee et al. (2002). The prior model (i.e., before data assimilation) is forced by 12-hourly wind stress, as well as daily surface heat flux and freshwater flux derived from the National Centers for Environmental Prediction (NCEP)/National Center for Atmospheric Research reanalysis product (Kalnay et al. 1996). The time mean values of these fluxes are replaced by those obtained from the Comprehensive OceanAtmosphere Data Set (COADS) (da Silva et al. 1994) to reduce biased estimates of equatorial currents incurred by the NCEP forcing (Lee et al. 2002). In addition to the forcing by the prescribed surface heat flux, model sea surface temperature (SST) is relaxed to NCEP values with time scales of 1-2 months using the formulation of Barnier et al. (1995). Sea surface salinity (SSS) is relaxed to the Boyer and Levitus (1998; hereafter BL98) seasonal climatology with a time scale of 1 month. A 10-year spin-up was initialized from BL98 temperature and salinity climatologies, followed by integration with forcing from 1993 to the present.

An approximate Kalman filter and smoother (Fukumori 2002) is then applied to assimilate sea-level anomalies from the Ocean Topography Experiment (TOPEX)/Poseidon and Jason-1 and -2 altimeters and in situ subsurface temperature anomalies obtained from a suite of Expendable Bathythermograph (XBT), Conductivity-Temperature-Depth, Argo and Tropical Atmosphere Ocean Project data (qualitycontrolled by D. Behringer of NCEP) from 1993 to present. As part of the assimilation procedure, the application of the smoother obtains new estimates of the wind stress by adjusting the variability of the prior NCEP wind stress to improve the consistency between the model output and available observations. This is similar to so-called adjoint methods where surface forcings are adjusted (from prior estimates) to improve the fit of the model to the data. The resultant estimates of wind stress are then used to force the model again along with the blended NCEP-COADS heat and freshwater fluxes and the SST and SSS relaxations. The resultant model run, satisfying the model equations exactly, is used for the analysis of MLT and MLS balances. Note that the tendencies due to SST and SSS relaxations, applied only to the top layer of the model, are used to compensate for some errors in the surface fluxes, possible model error, and to account for some feedback effect. They are included as part of the surface heat and freshwater flux tendencies. We have found the magnitudes of the relaxation contributions to be generally small compared to the prescribed surface fluxes themselves. Away from the top layer, there is no source/sink of heat or salt, so the heat and salt budgets close (satisfying the model's heat and salt conservation equations exactly). In other words, the estimated state is an exact solution of the underlying model.

ECCO-JPL products have already been used to analyze ML budgets in the Pacific and Indian Oceans (e.g., Kim et al. 2004, 2006, 2007; Halkides and Lee 2009; 2011 manuscript accepted for publication). Additional details on the model physics/configuration and on ML budget closure have been addressed extensively elsewhere, so for further information on these issues we refer readers to Lee et al. (2002) and Kim et al. (2006), respectively.

\subsection{Model data consistency}

Figure $2 \mathrm{a}-\mathrm{c}$ shows the simulated (black) and observed (red) seasonal anomalies of sea surface temperature (SST), salinity (SSS), and height (SSH) during 1993-2006 spatially averaged over $\left(120-138^{\circ} \mathrm{E}, 8-3^{\circ} \mathrm{S}\right.$; black box in Fig. 1). Observed SST is from the National Oceanic and Atmospheric Administration National Climatic Data Center level 4 Optimum Interpolation of SST with Advanced Very High Resolution Radiometer data (http:// ghrsst.jpl.nasa.gov ; Reynolds et al. 2007). Observed SSS is from BL98. Observed SSH is an Archiving Validation and Interpretation of Satellite Oceanographic (AVISO) altimeter product (http://www.aviso.oceanobs.com) that merges observations from several altimeters (TOPEX/ Poseidon, Jason-1, European Remote Sensing Satellite 1 and 2, Environmental Satellite and GeoSat Follow-On). Figure $2 \mathrm{~d}$ shows the seasonal surface wind stress anomaly observed by the NASA QuikSCAT satellite SeaWinds scatterometer (red) and estimated by the ECCO smoother (black) during 2000-2006, the time period for which QuikSCAT observations were available when this work was prepared. The wind stress maps were produced and distributed by the Institut français de recherche pour l'exploitation de la mer (http:/www.ifremer.fr/cersat/en/ index.htm) using level 2 swath data distributed by the Physical Oceanography Data Active Archive Center (PO. DAAC, http://podaac.jpl.nasa.gov). It is evident from Fig. 2 that the seasonal variabilities of the spatially averaged ECCO SST, SSS, SSH, and surface wind stress are all reasonably consistent with observations, both in phase and amplitude.

The spatial patterns of SST (e.g., Fig. 3a, b, used later on, which shows standard deviation of observed (ECCO) seasonal SST (MLT) tendency or time derivative of SST (MLT)), as well as those of SSS (Fig. 3c, d) and SSH (e.g., Fig. 4), also show reasonable consistency between ECCO and observations within the box on the seasonal timescale. Some differences between the observed and ECCO surface salinity patterns (Fig. 3c, d) are due to sampling and mapping errors associated with the observed climatology 
(a)

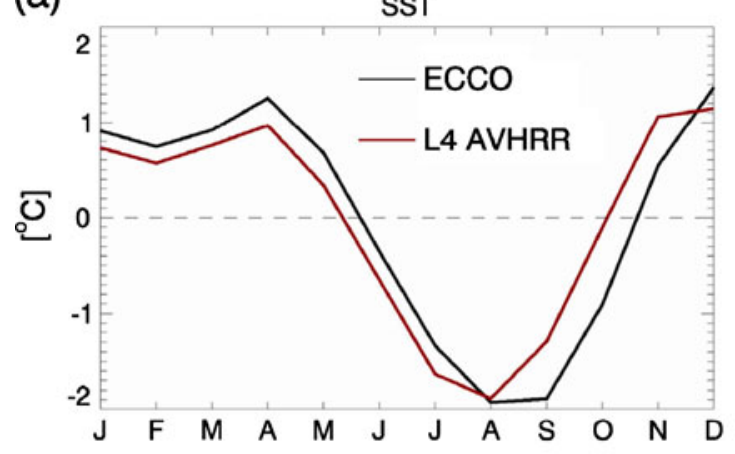

(c)

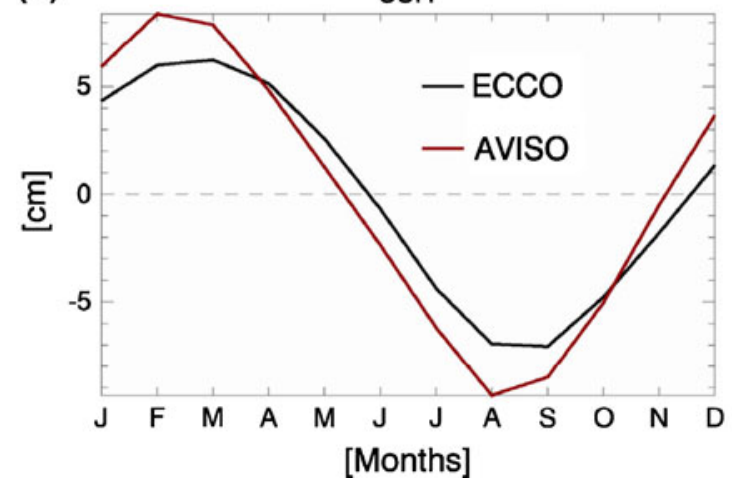

Fig. 2 Seasonal cycles for 1993-2006 (time means subtracted) over $120-138^{\circ} \mathrm{E}, 8-3^{\circ} \mathrm{S}$ of ECCO and observed a SST (observations from http://ghrsst.jpl.nasa.gov), b SSS (observations from LB98), c SSH

(e.g., the high-wavenumber noise in the climatological maps). Still the observed and simulated salinity patterns are quite similar qualitatively.

Figure 4 shows the observed and simulated spatial evolutions of the annual SSH minimum (e.g., also seen in Fig. 2c during August; discussed in more detail in "Results" section), which spreads northwestward from the Gulf of Carpentaria (see Fig. 1 for geography) across the Arafura Sea during June-September, when the seasonal MLT anomaly is also negative (e.g., Fig. 2a). Note that there is also an annual SSH maximum in this region during austral summer (e.g., Fig. 2c in February), the development of which is well simulated by ECCO (not shown). SSH variability can be used as a proxy for variability of pycnocline/thermocline depth. Pycnocline motion affects MLT and MLS through its effects on vertical advection of temperature and salinity and on the vertical temperature and salinity gradients near the ML base (see Eq. 2b, described in "ML budget equations" section). Thus, reasonable estimation of $\mathrm{SSH}$ reflects a reasonable estimation of the influence of vertical subsurface processes on MLT and MLS in our box-something that, unfortunately, cannot be verified directly due to a lack of subsurface observations in
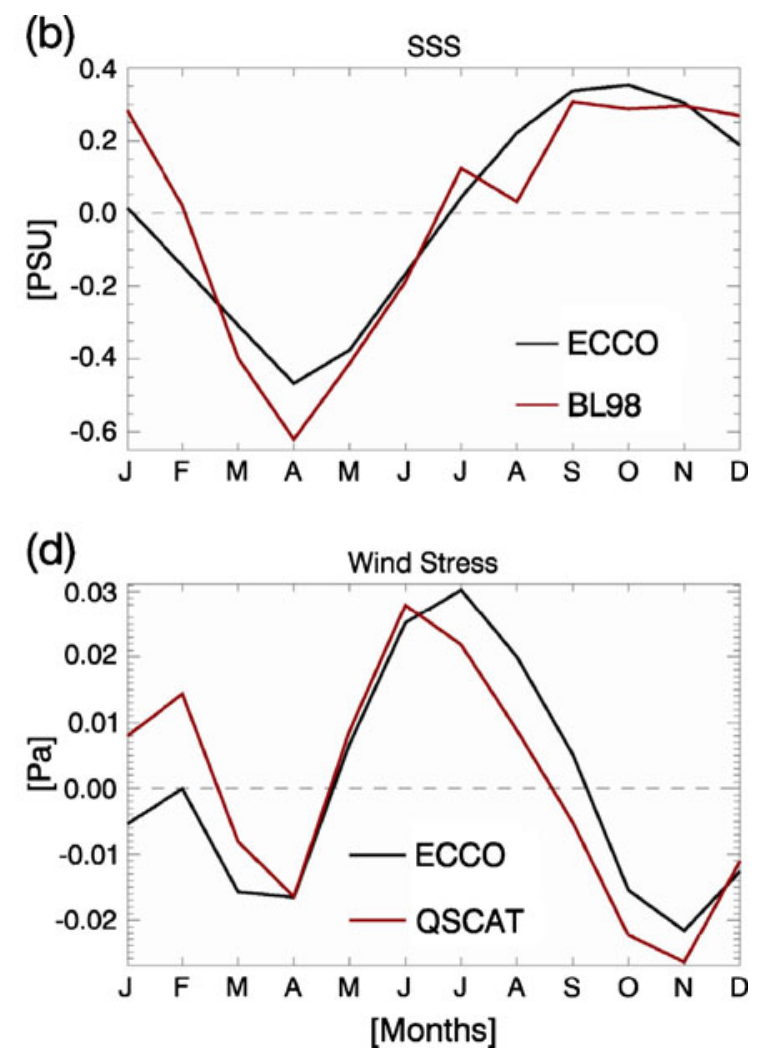

(observations from AVISO), and $\mathbf{d}$ surface wind stress anomaly for 2000-2006 (observations from NASA QuikSCAT satellite sea winds scatterometer)

this region. In this paper, we show that while local Ekman forcing of the pycnocline/upper thermocline (consistent with the SSH and wind curl patterns in Fig. 4) alone does not have a large direct impact on MLT in the Banda-Arafura Seas, it is still an important factor in determining the MLT budget as it modulates the temperature gradient near the ML base that is then available to be drawn into the ML by other processes (e.g., vertical turbulent mixing).

\subsection{ML budget equations}

Like most OGCMs used by existing ocean data assimilation or state-estimate systems, MITgcm is a Zcoordinate model that does not have a prognostic model to compute ML properties (e.g., depth, bulk temperature, and salinity) and their budgets directly. The KPP mixing scheme simulates enhanced upper-ocean vertical mixing processes, but upper-ocean properties are affected by additional processes as well (e.g., horizontal convergence). $Z$-coordinate models compute the tendencies of temperature and salinity prognostically on a fixed vertical grid. Our model's temperature equation at a given grid cell is 

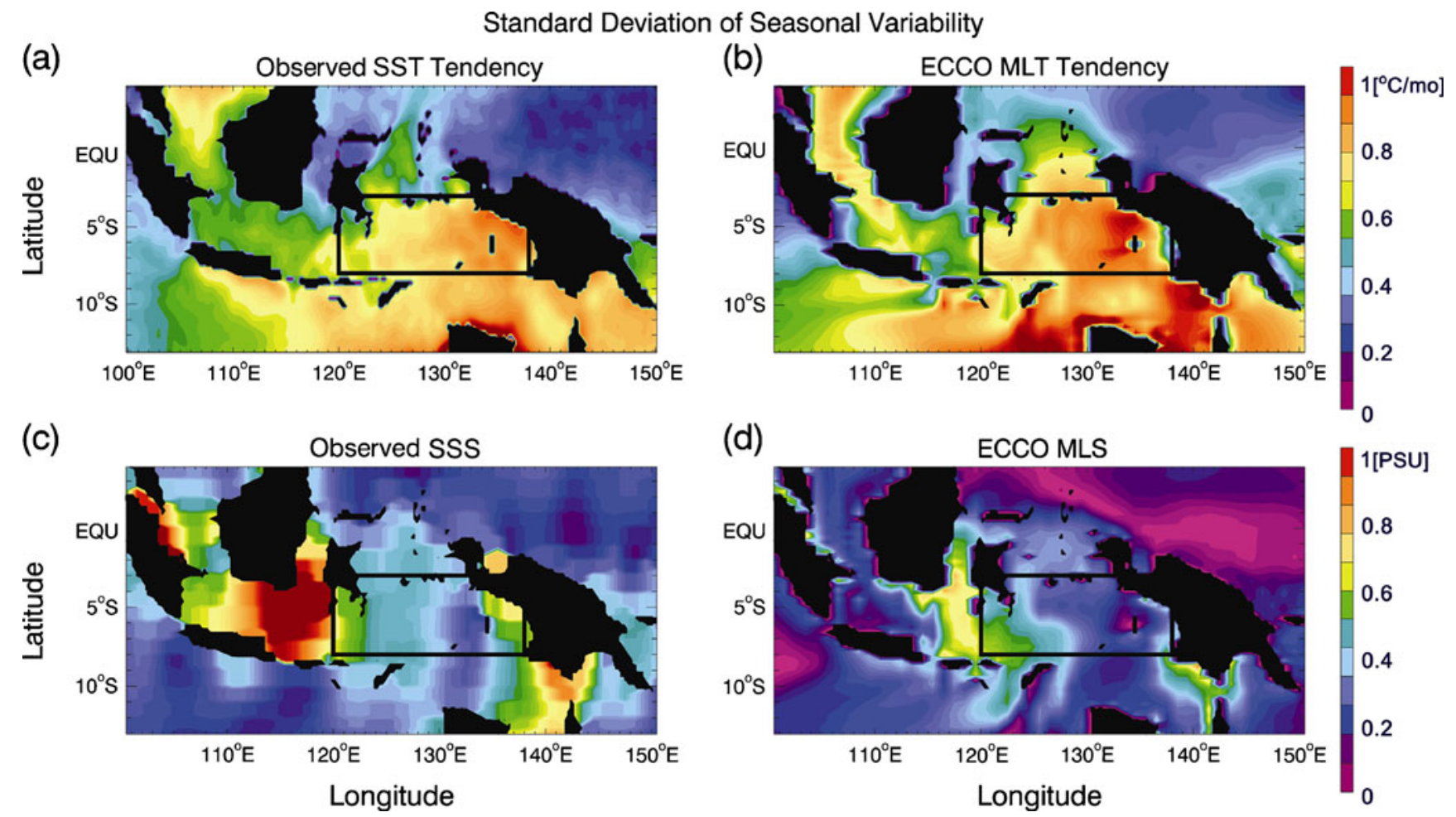

Fig. 3 Seasonal standard deviations for the a observed SST tendency (http://ghrsst.jpl.nasa.gov), b MLT tendency from ECCO, c sea surface salinity from LB98, and d MLS from ECCO. $\mathbf{c}$ and $\mathbf{d}$ compare

salinity, not salinity tendency, since we have only monthly values for observed SSS and the coarse temporal resolution would cause errors in the time derivative

written (with space and time indices $[x, y, z, t]$ omitted for simplicity) as follows:

$$
\begin{aligned}
\frac{\partial T}{\partial t}= & \frac{1}{\rho C_{\mathrm{p}}} \frac{\partial\left(Q_{\mathrm{net}}\right)}{\partial z}-\left(u \frac{\partial T}{\partial x}+v \frac{\partial T}{\partial y}+w \frac{\partial T}{\partial z}\right) \\
& +\left\{\frac{\partial}{\partial x}\left(K_{x} \frac{\partial T}{\partial x}\right)+\frac{\partial}{\partial y}\left(K_{y} \frac{\partial T}{\partial y}\right)+\frac{\partial}{\partial z}\left(K_{z} \frac{\partial T}{\partial z}\right)\right\}
\end{aligned}
$$

where $(u, v, w)$ are zonal, meridional, and vertical velocities; $\kappa_{x}$ and $\kappa_{y}$ are horizontal diffusive coefficients determined from horizontal background diffusivity and horizontal projection of diffusivity from GM mixing; $\kappa_{z}$ is vertical diffusivity determined from KPP mixing (including the so-called non-local transport, convection, background vertical diffusion, and the projection of GM mixing coefficients in the vertical direction); $\rho$ is density; $C_{\mathrm{p}}$ is specific heat of seawater. The parameter $Q_{\text {net }}$ equals $\left(Q_{S W} Q_{L W+} Q_{S H_{+}} Q_{L H_{+}} Q_{R}\right)$. Here, $Q_{S W}$ is prescribed as short-wave radiation flux, which is depth penetrating with an exponentially decaying profile, after Paulson and Simpson (1977). The latter is important for barrier layer formation (Schiller and Godfrey 2003) and thus subsurface effects on MLT; $Q_{\mathrm{LW}}, Q_{\mathrm{SH}}$, and $Q_{\mathrm{LH}}$ are the prescribed long-wave radiation, sensible heat, and latent heat fluxes

which, unlike $Q_{S W}$, affect the top model layer only and thus are set equal to zero for all model layers below the top layer. As mentioned in the "ECCO-JPL product description" section, the relaxation heat flux, $Q_{\mathrm{R}}=-\lambda\left(\mathrm{SST}_{\text {Model }}-\right.$ $\left.\mathrm{SST}_{\mathrm{Obs}}\right)$ compensates for some errors in the prescribed $\left(Q_{L W}+Q_{S H}+Q_{L H}\right)$ and accounts for some feedback effects, similar to using a bulk formula (see Lee et al. (2002) for details). The relaxation time scale, $1 / \lambda$, is $1-$ 2 months (1 month) for temperature (salinity) and determined using the Barnier et al. (1995) formulation based on NCEP forcing. $Q_{\mathrm{R}}$ is generally small compared to the total surface flux effect. Note that in Eq. 1 and in Eq. 2a below, $\partial\left(Q_{\text {net }}\right)$ represents the total increment of the surface heat flux that penetrates (is distributed over) a given model layer of thickness $\partial z$; below the top layer, $\partial\left(Q_{\text {net }}\right)$ only includes the penetrative short-wave radiation flux.

During integration, Eq. 1 right-hand side (RHS) terms at each fixed grid cell are accumulated hourly and archived at 2-day intervals, providing budget closure at each cell (e.g., Kim et al. 2006). To calculate the heat budget above a given depth, one integrates the tendency terms (Eq. 1 terms representing contributions to the time derivative of temperature by individual physical processes) from the surface down to that depth. We define the ML base at each location 
(a) June

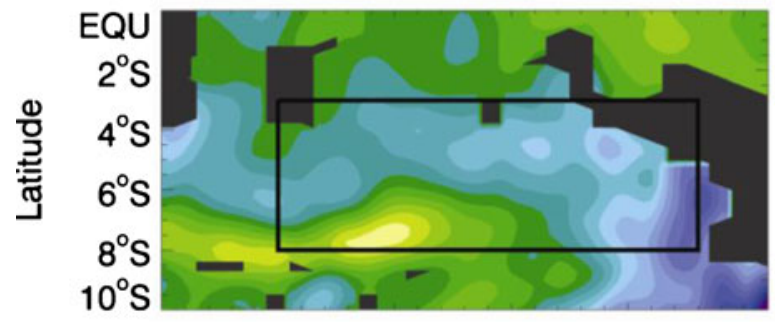

Observed

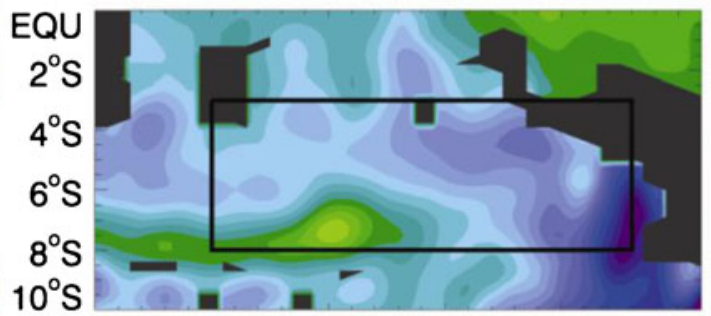

$115^{\circ} \mathrm{E} \quad 120^{\circ} \mathrm{E} \quad 125^{\circ} \mathrm{E} \quad 130^{\circ} \mathrm{E} \quad 135^{\circ} \mathrm{E} \quad 140^{\circ} \mathrm{E} \quad 115^{\circ} \mathrm{E} \quad 120^{\circ} \mathrm{E} \quad 125^{\circ} \mathrm{E} \quad 130^{\circ} \mathrm{E} \quad 135^{\circ} \mathrm{E} \quad 140^{\circ} \mathrm{E}$ (c) August

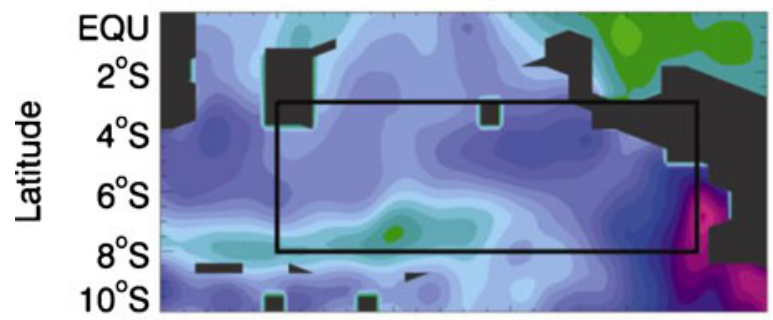

(d) September

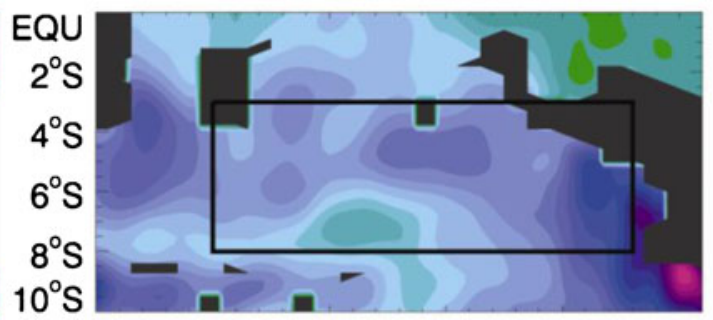

$115^{\circ} \mathrm{E} \quad 120^{\circ} \mathrm{E} \quad 125^{\circ} \mathrm{E} \quad 130^{\circ} \mathrm{E} \quad 135^{\circ} \mathrm{E} \quad 140^{\circ} \mathrm{E} \quad 115^{\circ} \mathrm{E} \quad 120^{\circ} \mathrm{E} \quad 125^{\circ} \mathrm{E} \quad 130^{\circ} \mathrm{E} \quad 135^{\circ} \mathrm{E} \quad 140^{\circ} \mathrm{E}$

(e) June

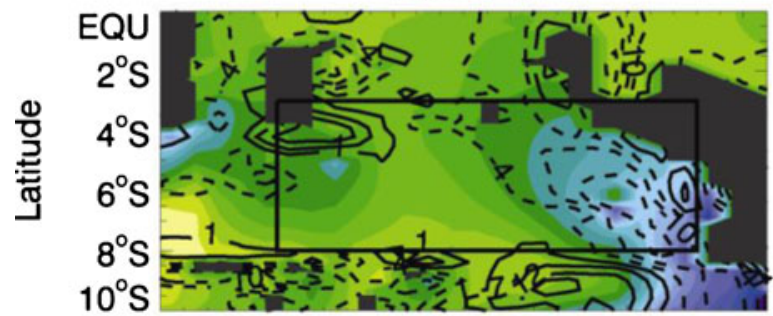

ECCO

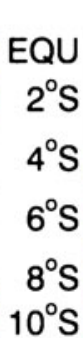

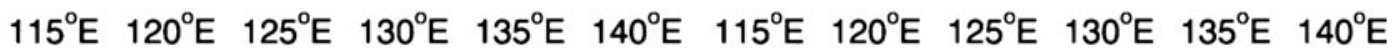

(g) August

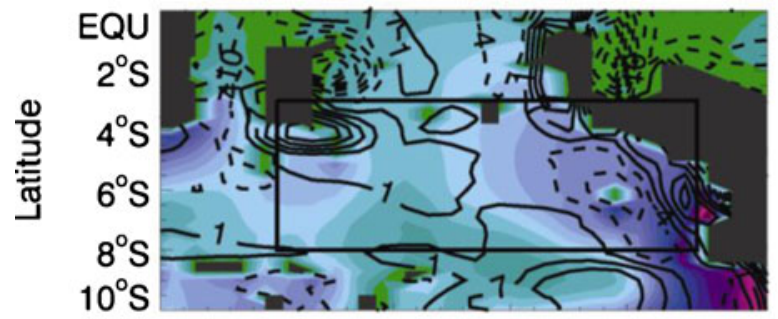

(h) September

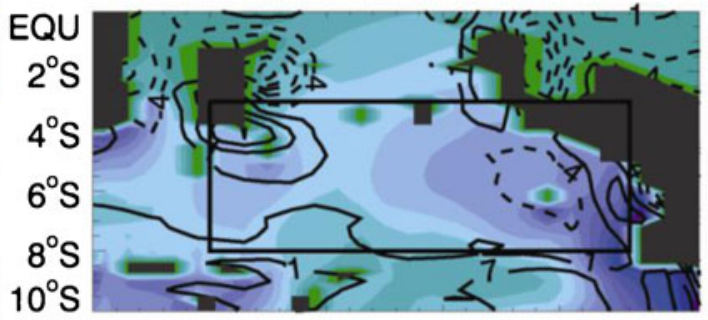

\section{Longitude \\ Longitude \\ $\left.\begin{array}{lllllllllllll}-30 & -25 & -20 & -15 & -10 & -5 & 0 & 5 & 10 & 15 & 20 & 25 & {[\mathrm{~cm}]}\end{array}\right]$}

Fig. 4 Select months (June-September) from the seasonal cycle (1993-2006) of SSH [cm]. (a-d) Observations from AVISO altimeter product (http://www.aviso.oceanobs.com); (e-h) SSH from the ECCO ocean state estimate. Line contours in panels (e-h) show wind stress curl in units of $\left[10^{-8} \cdot \mathrm{Pa} / \mathrm{m}\right]$ calculated from the ECCO wind stress. Dashed (solid) lines are negative (positive) values with a contour interval of about $5.9 \times 10^{-8}[\mathrm{~Pa} / \mathrm{m}]$ 
and time as the depth $z$ at which $\sigma(z)=\sigma_{0}+0.125 \mathrm{kgm}^{-3}$, where $\sigma_{0}$ is surface potential density. This density offset corresponds to a $0.5^{\circ} \mathrm{C}$ temperature offset at $35 \mathrm{psu}$ and $20^{\circ}$ $\mathrm{C}$, which is an empirically based criteria commonly used to derive MLH from temperature profiles in the tropics (e.g., Price et al. 1986; Kelly and Qiu 1995; Obata et al. 1996; Monterey and Levitus 1997; Kessler et al. 1998; McPhaden 2002; many others). It has also been applied in several previous studies using ECCO output (e.g., Kim et al. 2006, 2007; Halkides and Lee 2009; 2011 manuscript accepted for publication). As a result of using a threshold criterion to define MLH, the ML exhibits a weak vertical stratification, the effect of which must be accounted for as the ML base varies in time; thus, the effect on MLT of entrainment (detrainment) into (out of) the ML due to motion of the ML base must be computed off-line. The resultant MLT budget is described by a diagnostic MLT tendency equation that is rigorously derived in Kim et al. (2006) and used in several subsequent publications. For simplicity, we do not repeat the derivation here but just present the equation along with a brief description of the physical interpretation.

Denoting vertical integration over the ML by square brackets and temporarily grouping vertical subsurface processes into one "subsurface" term (representing vertical exchange with the ocean beneath the ML), the MLT time tendency can be written as

$$
\begin{aligned}
{\left[\frac{\partial T}{\partial t}\right]=} & {\left[\frac{1}{\rho C_{p}} \frac{\partial\left(Q_{\text {net }}\right)}{\partial z}\right]-\left[u \frac{\partial T}{\partial x}+v \frac{\partial T}{\partial y}\right] } \\
& +\left[\frac{\partial}{\partial x}\left(k_{x} \frac{\partial T}{\partial x}\right)+\frac{\partial}{\partial y}\left(k_{y} \frac{\partial T}{\partial y}\right)\right] \\
& + \text { subsurface }
\end{aligned}
$$

RHS terms represent contributions to MLT due to net surface heat flux $\left(Q_{n e t}=Q_{S W} Q_{L W}+Q_{S H}+Q_{L H}+Q_{R}\right.$ as described above), horizontal advection, horizontal mixing, and vertical subsurface processes. These subsurface processes are described by

$$
\begin{aligned}
& \text { subsurface }=-\frac{1}{h} \Delta T \frac{\partial h}{\partial t}-\left[w \frac{\partial T}{\partial z}\right]-\left.\frac{1}{h} K \frac{\partial T}{\partial z}\right|_{-h} \\
& \Delta T= \begin{cases}{[T]-T_{\text {det }}\left(\frac{\partial h}{\partial t}<0\right)} \\
0 & \left(\frac{\partial h}{\partial t}=0\right) \\
{[T]-T_{\text {ent }}} & \left(\frac{\partial h}{\partial t}>0\right)\end{cases}
\end{aligned}
$$

where $h$ is the spatiotemporally varying MLH; $\frac{\partial h}{\partial t}$ is the vertical velocity of the ML base; $\Delta T$ is the difference between the vertically averaged MLT, or [T], and either the detrainment temperature $T_{\text {det }}$ (temperature of water shed from the lower ML when the ML base shoals; $\frac{\partial h}{\partial t}<0$ ) or the entrainment temperature $T_{\text {ent }}$ (temperature of water drawn into the ML when the ML thickens; $\left.\frac{\partial h}{\partial t}>0\right)$. Respectively, Eq. 2b RHS terms represent the effects on MLT of (1) entrainment-detrainment; (2) vertical advection from below the ML base (note: this term, which is most closely associated with the effects of pycnocline/thermocline motion on the water column, would be equal to $-\left.\frac{1}{h}\left(w \frac{\partial T}{\partial z}\right)\right|_{z=-h}=$ $-\left.\frac{1}{h} w\right|_{z=-h} \cdot \Delta T$ for a perfectly mixed/unstratified ML); and (3) combined vertical turbulent/KPP mixing and diffusion across ML base. The latter term is not shown in square brackets because it is the vertical integral of the term evaluated at the ML base only; the portion of the integral evaluated at the surface boundary condition $-\left.\frac{1}{h} k \frac{\partial T}{\partial z}\right|_{0}$ is equivalent to the sum of the outgoing long-wave, sensible, and latent heat flux effects on the MLT (e.g., Kim et al. 2006), which are included in term 1 of Eq. 2a. The component of the entrainment-detrainment effect associated with lateral advection across the ML base is small in the tropics (Kim et al. 2007) and included in the horizontal advection term. The horizontal diffusive mixing effect (Eq. 2a term 3) is verifiably negligible, so we have excluded it from our results in subsequent sections for simplicity.

Note that, in the case of a perfectly uniform ML, the first two terms of Eq. $2 b$ together give the diabatic vertical advection of heat across the base of the ML or $-\frac{1}{h}\left(\frac{\partial h}{\partial t}+\left.w\right|_{z=-h}\right) \Delta T$. This is traditionally written as $-\frac{1}{h} w^{*} \Delta T$, where $w^{*}=\frac{\partial h}{\partial t}+\left.w\right|_{z=-h}$ represents the velocity of water relative to the moving $\mathrm{ML}$ base. If no water is being advected across the ML base, then $-\frac{1}{h} w^{*} \Delta T=0$. This occurs if the ML base moves at the same rate as the thermocline.

The entrainment-detrainment term (term 1 in Eq. 2b) may not be familiar to some readers since the MLT equations used in most literature only account for entrainment (and not detrainment) effects on MLT. This is due to the assumption of a perfectly mixed ML: If there is no vertical stratification (e.g., in a slab ML model), MLT is not affected by shoaling of the ML base because the water shed from the lower ML during this process has the same temperature as the vertical mean MLT, i.e., $[T]-T_{\text {det }}=0$. However, when the ML base is determined diagnostically from data or $z$-level model output using a threshold criteria (e.g., the depth $z$ at which $T(z)=T_{0}-0.5^{\circ} \mathrm{C}$ or analogously where $\sigma(z)=\sigma_{0}+0.125 \mathrm{kgm}^{-3}$ ), a weak stratification often exists. In this case, when the ML base shoals $\left(\frac{\partial h}{\partial t}<0\right)$, it sheds water that is somewhat colder than the vertical mean MLT. This loss of colder water can have a measurable warming effect on vertically averaged MLT, which accumulates in time (Kim et al. 2006). The MLT budget cannot be closed without accounting for this detrainment warming effect, and ignoring this detrainment 
effect is one of the main reasons for the difficulty many researchers have in closing MLT budgets derived from Zcoordinate model output.

All tendency terms in Eq. 2 excepting the entrainmentdetrainment term can be directly obtained by vertically averaging Eq. 1 tendency outputs archived by the model from the surface to the ML base. The entrainmentdetrainment tendency is estimated using the model output of $T$ and the diagnostically derived $h$. The model salinity and MLS equations are identical to Eqs. 1 and $2 \mathrm{a}-\mathrm{c}$, respectively, except that $T(x, y, z, t)$ is replaced by salinity, $S(x, y, z, t)$, and the surface heat flux term is replaced by a virtual freshwater flux representing the net effects of precipitation, evaporation, and freshwater run-off.

\section{Results}

We analyze the seasonal cycles for years 1993-2006 (time means removed) of the monthly averaged MLT and MLS budgets over $120-138^{\circ} \mathrm{E}, 8-3^{\circ} \mathrm{S}$, hereafter referred as "the box." In this region, the variability of the seasonal MLT tendency tends to be large, and both the MLT and MLS tendencies are qualitatively more uniform than what is seen in the western marginal seas (e.g., Fig. 3).

\subsection{The seasonal MLT budget}

Figure 5a shows the net seasonal MLT tendency (black) and its contributions due to surface heat flux (red) and net ocean processes (dark green). The net tendency is strongly negative (positive) in May-August (SeptemberDecember and March, the monsoon transition seasons). Surface heat flux effects make the largest contributions to seasonal MLT. Combined ocean processes make a significant reinforcing contribution (discussed further later) that is comparable in amplitude to the surface flux tendency from January-April, but only two thirds of the amplitude of the surface flux term during the May-July minimum.

The surface flux term accounts for $\sim 60 \%$ of the net tendency during the large May-August cooling phase, which corresponds to both austral winter and the southeast monsoon period. During this time, surface shortwave flux is minimal since the insolation maximum is in the northern hemisphere. Concurrently, the regional winds are strengthened by the southeast monsoon (Fig. 2d, May-August) and near-surface humidity is relatively low (not shown), facilitating latent heat loss. During the warming phase in September-December (March), when the insolation maximum crosses our box and local winds are weak relative to the time mean in association with the semi-annual monsoon transition, surface heat flux causes

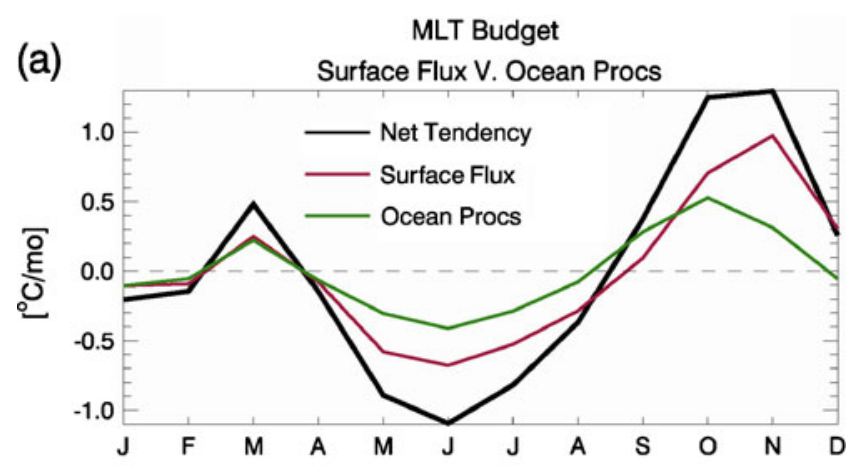

(b) Ocean Process Contributions

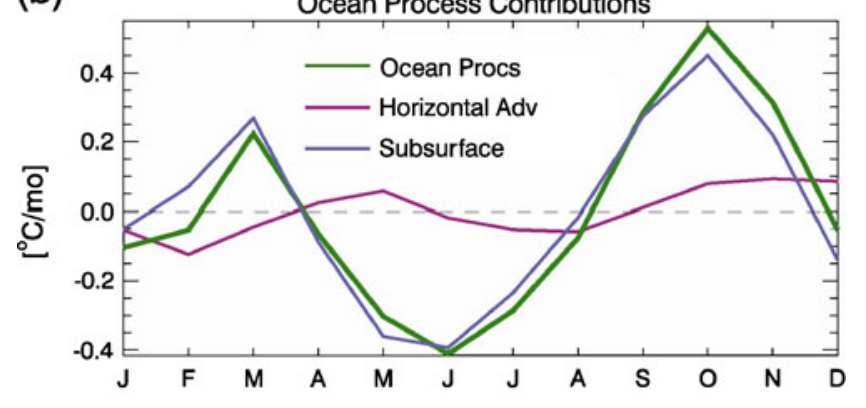

(c)

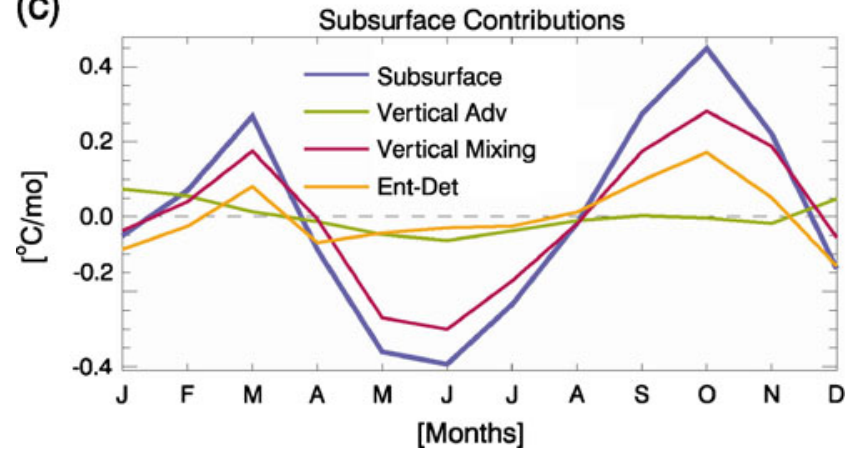

Fig. 5 Seasonal cycles for 1993-2006 (time means removed) of the ECCO MLT budget components spatially averaged over $\left(120-138^{\circ} \mathrm{E}\right.$, $\left.8-3^{\circ} \mathrm{S}\right)$ : a net tendency (black), surface flux (red), and ocean process (dark green) contributions; b decomposition of ocean process contribution: net ocean processes (dark green, same as the curve in a), horizontal advection (fuchsia), and vertical subsurface processes (blue); c decomposition of vertical subsurface process contribution: net vertical subsurface processes (blue, same as the curve in b), vertical advection (light green), turbulent vertical mixing (light red; includes effects of KPP mixing and diffusion), entrainment-detrainment (orange)

up to $75 \%(50 \%)$ of the positive MLT tendency anomaly (Fig. 5a). Mild cooling in January-February occurs due to a relative reduction in surface heat flux into the ocean when the insolation maximum passes south of our box (not shown); during this time, shortwave radiation is reduced and the northwest monsoon winds develop (Fig. 2d, February), contributing to anomalous heat loss by the ocean (i.e., reduction of surface heat flux into the ocean).

An interesting characteristic of the seasonal MLT anomaly itself (Fig. 2a) is the large amplitude of its annual 
(a) MLT $\left[{ }^{\circ} \mathrm{C}\right]$

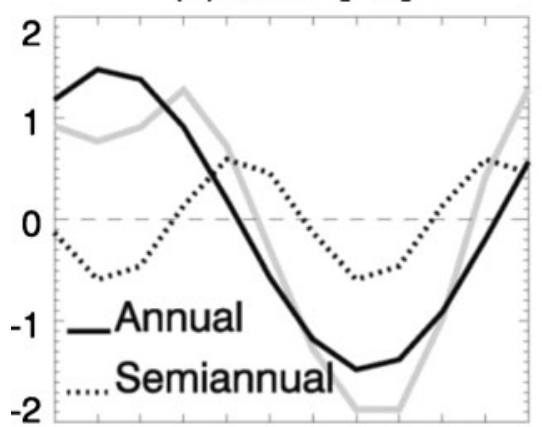

JFMAM J JASOND (b) Wind Stress [Pa]

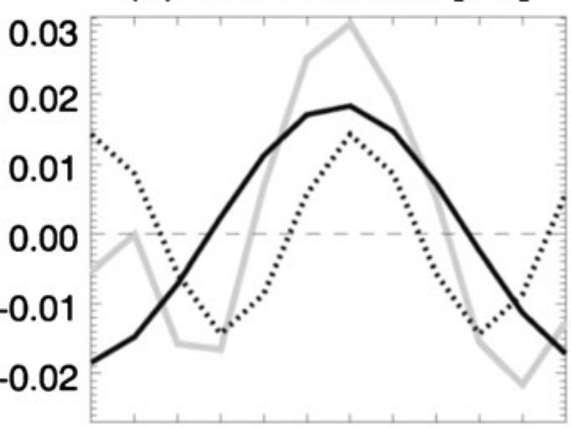

J F M A M J J A SON D (c) $\mathrm{MLH}[\mathrm{m}]$

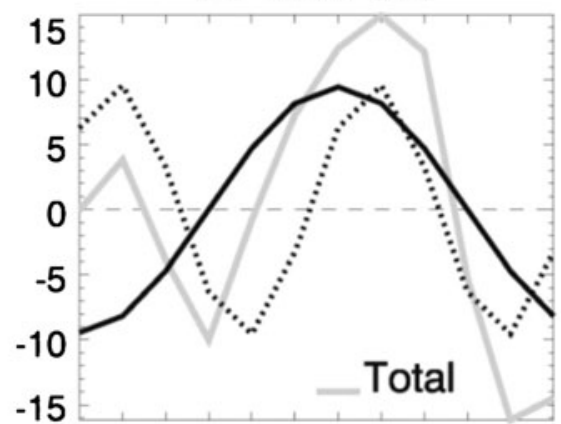

JFMAM J JASOND

MLT Budget Contributions

(d) Ocean Processes

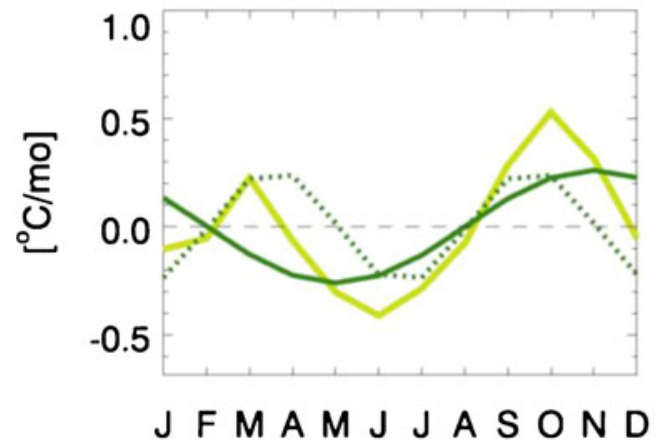

(e) Surface Heat Flux

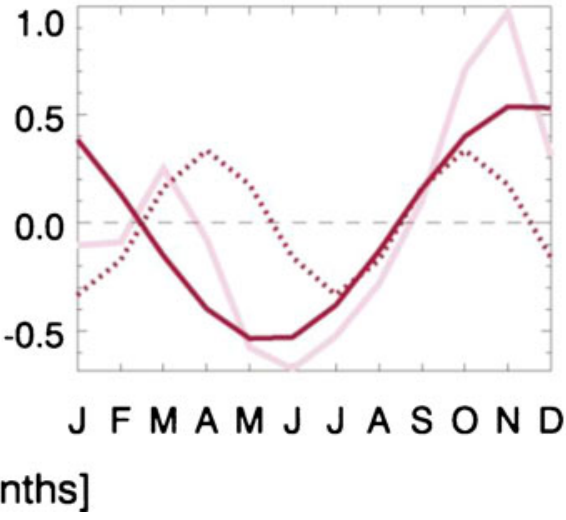

month], e the MLT tendency due to net surface heat flux $\left[{ }^{\circ} \mathrm{C} / \mathrm{month}\right]$. Faded solid lines show total signal for comparison

maximum falls south of our box in January-February, it is still much closer to the box than when the insolation maximum is in the northern hemisphere, e.g., May-August. As a result, the negative tendency anomaly that occurs in January-February is considerably smaller than the negative anomaly in May-August. Additionally, the positive anomaly in March (Fig. 6e) is much smaller than that during OctoberNovember due to a larger reduction in latent heat loss and a greater increase in solar heating relative to the previous months during October-November (which follows the MLT minimum and southwest monsoon). This strengthens the annual harmonic in MLT.

Next, we focus on the role of ocean dynamics. Figure $5 b$, which displays the decomposition of the ocean process term into horizontal advection (fuchsia curve) and vertical subsurface processes (blue curve; Eq. 2b), shows that the subsurface processes clearly dominate the ocean process contribution to MLT. Figure $5 \mathrm{c}$ further breaks down the subsurface term into components due to vertical entrainment-detrainment (orange), vertical advection (light green), and vertical turbulent mixing/diffusion (light maximum crosses over it. However, when the insolation 
red). The subsurface term is primarily controlled by vertical turbulent mixing, with secondary reinforcing contributions by entrainment-detrainment during March and September-November. The vertical advection term (light green curve; Eq. 2b term 2) is unexpectedly small (discussed momentarily); spatial averaging may have masked out some large local values of MLT change due to vertical advection, however, an inspection of the $2 \mathrm{D}$ plots (not shown) of the tendency terms indicates that this is generally not the case.

The small contribution by vertical advection is interesting since prior studies using limited in situ measurements and satellite wind data imply that Ekman suction (in our model, related to vertical advection at the ML base) associated with annual variability of the monsoon winds might be important to austral winter cooling in the Banda Sea (e.g., Wyrtki 1962; Gordon and Susanto 2001; Sprintall and Liu 2005; Qu et al. 2005). It is also well known that $\mathrm{SSH}$, a common proxy for pycnocline/thermocline depth, exhibits a strong annual minimum in the Gulf of Carpentaria and along the Arafura shelf in June-September (e.g., Fig. 4). This SSH minimum is associated with annual, upwellingfavorable, negative wind stress curl, especially in June-July (Fig. 4e, f). Note that, here, we show maps of the wind curl superimposed over the SSH for ECCO only (QuikSCAT wind stress curl is very noisy in this region). As the southeast monsoon develops, the negative wind

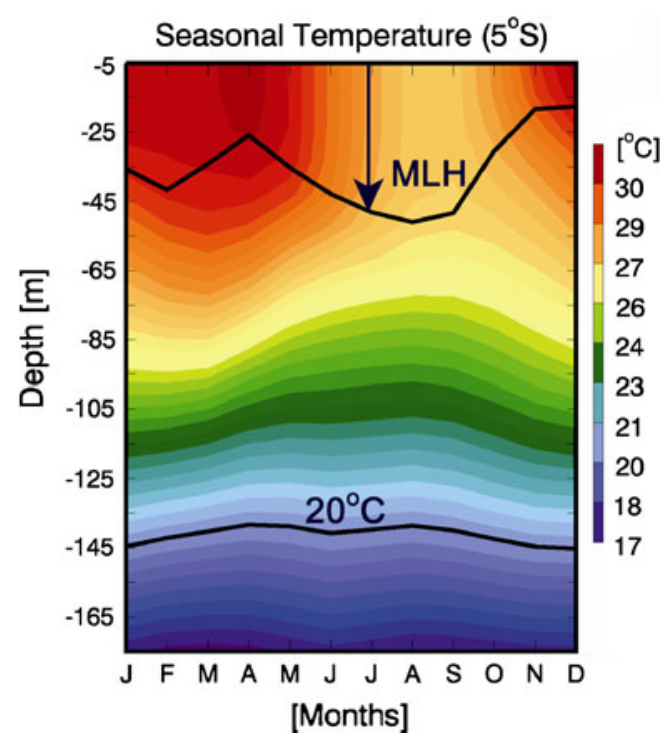

Fig. 7 Seasonal climatology (seasonal cycle plus time mean for 1993-2006) of the vertical temperature profile (depth versus time) along latitude $5^{\circ} \mathrm{S}$, averaged zonally over $125-134^{\circ} \mathrm{E}$, which is a sample cross-section within the index region shown in Fig. 1 that avoids major topographical features. Units are in degree Celsius. The seasonal cycles of the depths of the ML base and the $20^{\circ} \mathrm{C}$ isotherm (a proxy for central thermocline depth) are superimposed to help illustrate the raising of the isotherms of the upper thermocline during austral winter and the variability of the ML base curl (a proxy for Ekman upwelling) progressively raises the upper thermocline (e.g., Fig. 7, colored contours between the $20^{\circ} \mathrm{C}$ isotherm and ML base) northward and westward along the west coast of New Guinea (Fig. 4f-h). This is consistent with the synchronicity of the highly annual seasonal cycles of SSH and MLT in our box (Fig. 2a, c).

So why then is the vertical advection effect on MLT small and the effect of vertical turbulent mixing so large? Vertical profiles of the temperature structure across the box (e.g., Fig. 7) indicate that the reason for the small vertical advection contribution in Fig. $5 \mathrm{c}$ is that, despite annual uplift of the upper thermocline in austral winter, the cooler sub-thermocline water does not come sufficiently close to the ML base on its own to have a significant direct affect on MLT without the aid of additional processes. We assert that, first, a combination of local Ekman forcing and propagation of thermocline signals (e.g., from the Gulf of Carpentaria) causes the upper thermocline in our box to shoal during austral winter (e.g., May to September for the cross-section in Fig. 7), pulling cool subsurface water closer to the ML base, and that this increases the vertical temperature gradient beneath the ML base; then, as that upper thermocline anomaly propagates westward, development of the southwest monsoon winds in June-August (Fig. 2d) drives an increase in wind-driven vertical diffusivity (coefficient in Eq. 2b term 3). This causes the ML base to deepen (Fig. 7, upper solid black line), and the relatively cool thermocline water below the ML base is incorporated into the ML via turbulent vertical mixing.

This result is consistent with finestructure measurements by Ffield and Robertson (2008) and a few other studies, which have suggested that turbulent mixing is prominent in the Banda and Arafura Seas. This mixing may be related to several factors, such as the monsoon winds, complex topography/bathymetry, and tides (the effects of which would rectify into the seasonal cycle).

Note that Kida and Richards (2009) also report on the importance of upwelling over the Arafura shelf in causing the August MLT minimum in the Banda-Arafura Seas region; however, their idealized box model study examines bathymetric effects on lateral advection into the Arafura Sea and ensuing enhancement of shelf upwelling along a $50-\mathrm{m}$ shelf right along the coast of New Guinea. While the ECCO model is generally more realistic than their idealized model (in that ECCO includes a greater number of processes), ECCO does not resolve the regional bathymetry along the coast to a resolution comparable to Kida and Richards' $50-\mathrm{m}$ shelf; thus, a higher resolution product is needed to study the effect on regional MLT of the detailed bathymetry right along the coast.

Lastly, the positive MLT tendency anomalies associated with the vertical turbulent mixing and entrainment terms (Fig. 5c) in March and in September-November are 
associated with the relaxation of local winds during monsoon transitions (Fig. 2d). This semiannual variability may also be enhanced by remote forcing of the pycnocline/ thermocline associated with the Wyrtki Jets in the equatorial Indian Ocean or with remotely generated signals from the Pacific Ocean (e.g., Wijffels and Meyers 2004; Qu et al 2008; Gordon et al. 2008). Additional work is needed, e.g., model sensitivity experiments, to test/separate the role of remotely forced waves on MLT in this region. However, we suspect that the topographical break between the Banda and Arafura Seas (e.g., see bathymetry in Fig. 1) reduces the remote effects in much of our box compared to the surrounding marginal seas. For example, XBT data described in Wijffels and Meyers (2004) indicate that the shelf break dividing the Banda and Arafura Seas diverts the pathway of remotely forced waves from the Pacific to the west of the Arafura Sea and that annual variability dominates the seasonal cycle of thermocline variability in the Arafura Sea region. This is consistent with our Figs. 2c, 4, and 7. Additionally, the interannual variability of the vertical temperature profile in the cross-sections of our box, e.g., Fig. 8, is qualitatively consistent with the finding of Wijffels and Meyers (2004) during 1993-2002 (the period covered by both studies), showing notable semiannual variability at depths associated with the ML base, but with predominantly annual variability below the ML (where remotely generated waves would travel).

In summary, winter ML cooling in the Banda-Arafura Seas is predominantly caused by a combination of increased surface heat loss and cooling by turbulent vertical mixing that is modulated by Ekman suction during the southeast monsoon period. Semiannual warming during the monsoon transition periods is associated with the insolation maximum passing over the box (enhancing surface heating) and reductions in both surface heat loss and in vertical

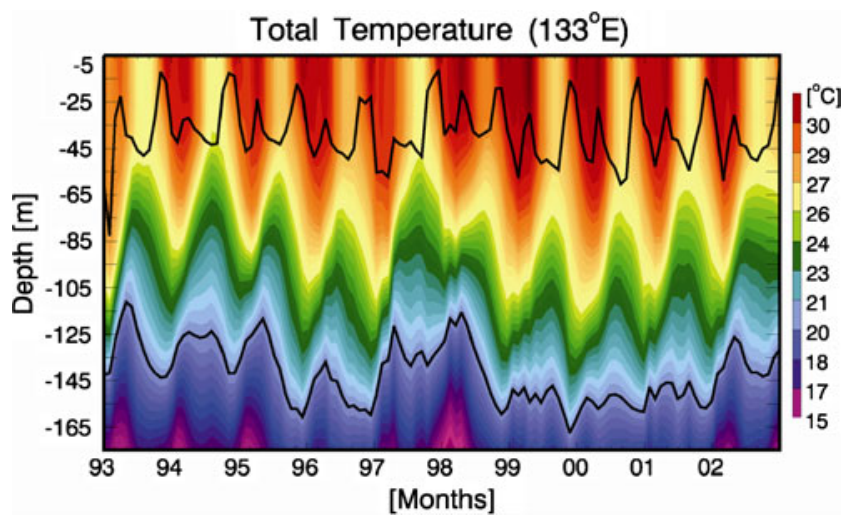

Fig. 8 Vertical profile of the total temperature signal during 19932002 along $133^{\circ}$ E. This panel is an example of the reasonable consistency between ECCO vertical temperature profiles in our box and observations presented by Wijffels and Meyers (2004) (their Fig. 7b). We show the time period for which the two studies overlap
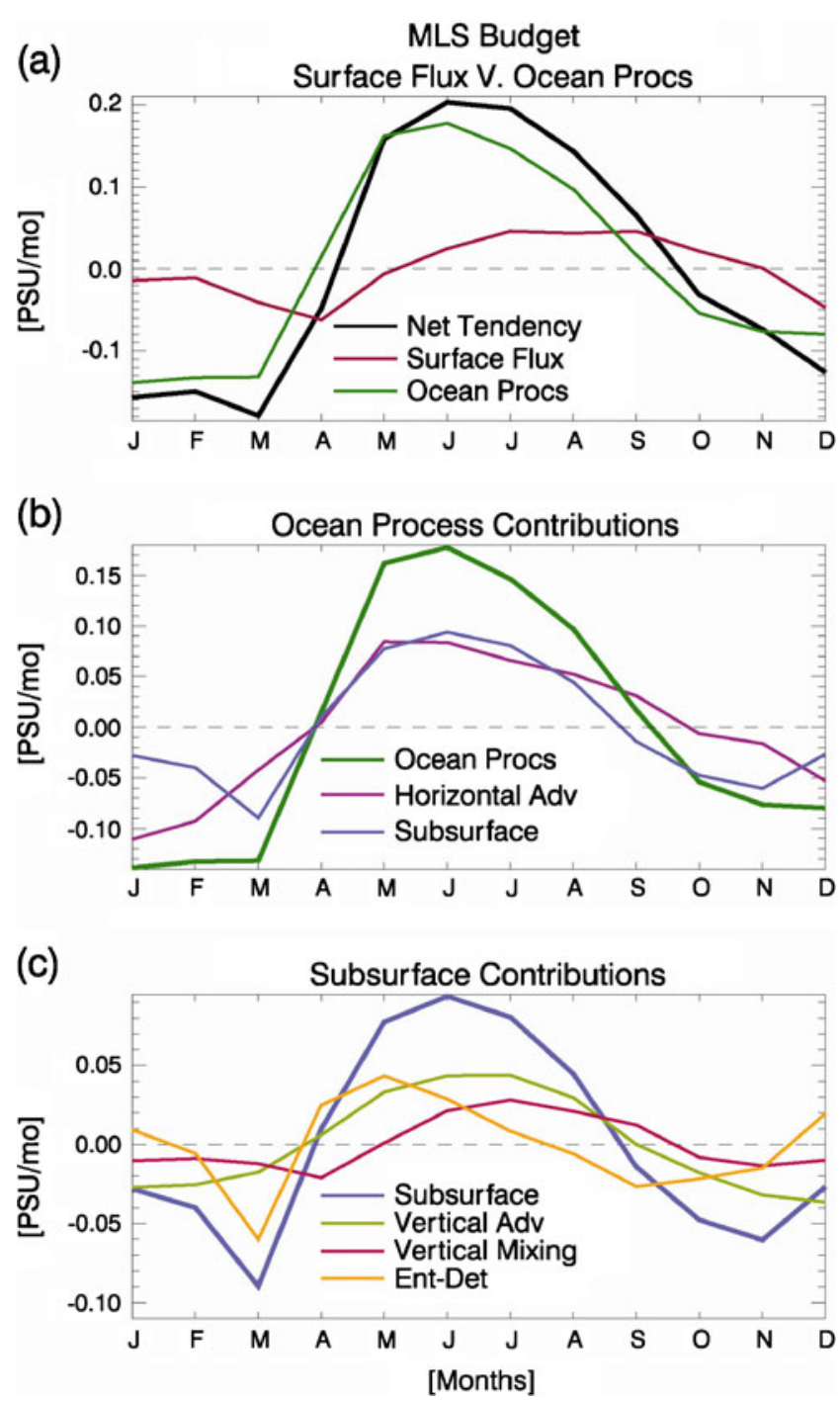

Fig. 9 a-c Same as Fig. 5 but for the MLS budget. Units $=$ psu/month

mixing and entrainment cooling when the local winds die down during these same months. Additional work is needed to understand the roles, if any, of remotely generated waves and of coastal topography on MLT in this region.

\subsection{The seasonal MLS budget}

MLS in the Banda-Arafura area exhibits a more complicated spatial distribution than MLT due to the interaction between coastal run-off, water masses entering through different ITF pathways, and the complex regional circulation patterns. However, its area mean seasonal cycle is characterized by annual variability (e.g., Wyrtki 1961; Figs. $2 \mathrm{~b}$ and 9a), and its amplitude tends to be small compared to the seasonal cycles of MLS in the Flores Sea to the west and in the Torres Strait/Gulf of Carpentaria to the southeast (Fig. 3c, d). Figure 9a shows the box average seasonal MLS tendency (black) and contributions to MLS 
Fig. 10 Vertical profiles (depth versus time) of nondimensionalized seasonal anomaly of a salinity and $\mathbf{b}$ temperature from ECCO spatially averaged along $7^{\circ} \mathrm{S}$; $131-136^{\circ} \mathrm{S}$, near the southeast corner of our box. Salinity and temperature anomalies here are non-dimensionalized by multiplication with the saline contraction coefficient $\left(\beta=7.9 \times 10^{-4} \mathrm{ppt}^{-1}\right)$ and the thermal expansion coefficient $\left(\alpha=1.5 \times 10^{-4}{ }^{\circ} \mathrm{C}^{-1}\right)$, respectively. Solid black lines show the MLH (depth of the ML base) and $20^{\circ} \mathrm{C}$ isotherm

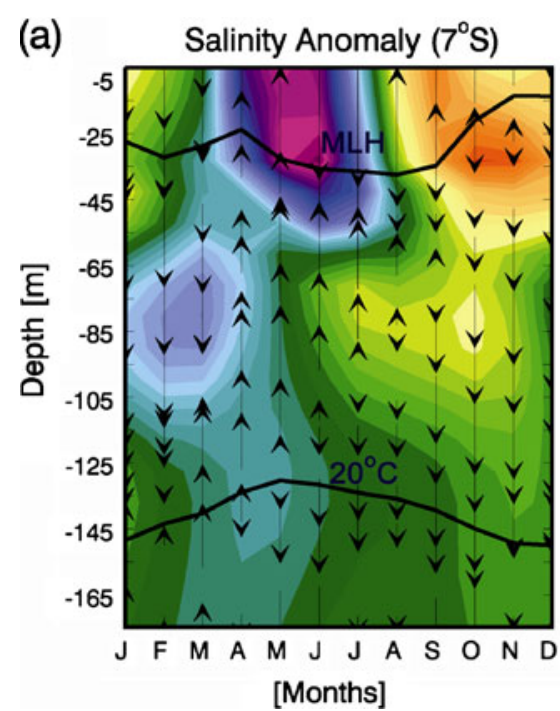

(b) Temperature Anomaly $\left(7^{\circ} \mathrm{S}\right)$

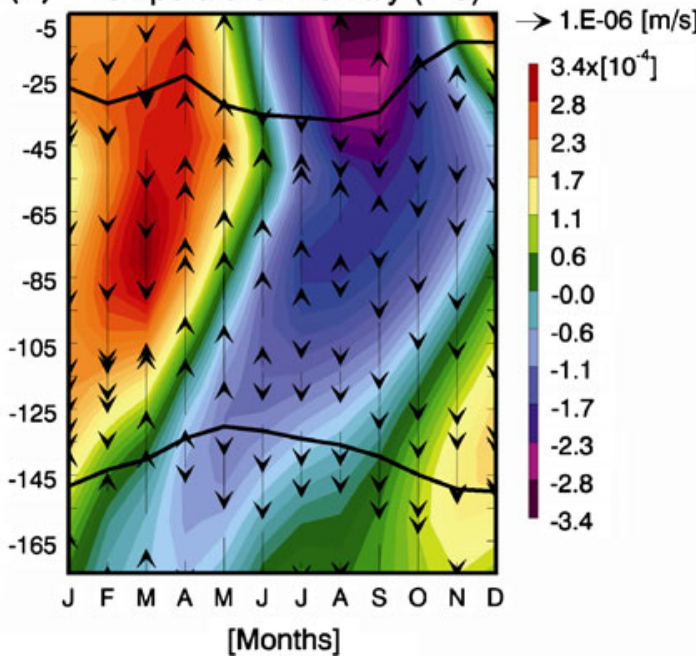

by surface freshwater flux (red curve) and ocean processes (dark green). The total seasonal MLS tendency is positive (negative) during May-September (October-April). Generally, ocean processes dominate. A secondary contribution by surface freshwater flux largely reflects the influence of semiannual rainfall during the monsoon transitions, especially in March-April, and of enhanced evaporation (causing relative salinization) associated with the southeast monsoon winds in June-September. Figure 9b shows that horizontal advection and vertical subsurface effects make comparable contributions to the ocean process term, especially to the positive anomaly in April-September. The subsurface term, however, exhibits some semiannual variability while the horizontal advection term does not.

Figure $9 \mathrm{c}$ shows the decomposition of the subsurface term into vertical entrainment-detrainment (orange), vertical advection (light green), and vertical mixing/diffusion (light red) contributions to the MLS tendency. Negative MLS tendency anomalies due to entrainment-detrainment in February-March and in September-November can be attributed to detrainment of relatively salty water from the ML base as the ML base shoals during these months, as seen in Fig. 10a (upper black line) for a cross-section in the southeast corner of our box (this particular cross-section was chosen for use later on, but for our purposes here it is fairly representative of the box as a whole). These negative MLS tendency anomalies are followed by positive anomalies in April-June and in December-January, respectively (Fig. 9c). The latter correspond to deepening of the ML (e.g., Fig. 10a, May and January), which causes relatively salty water to be entrained into the ML.

Similar arguments can be made for the positive MLS tendency anomalies during May-August (Fig. 9c) associated with the vertical turbulent mixing and vertical advection terms, as follows. During the southwest monsoon, winddriven vertical diffusivity/mixing increases (as evidenced by the ML deepening seen in Fig. 10a) and wind curl (Fig. 4e, f) raises the pycnocline, causing upward advection across the ML base (e.g., vectors in Fig. 10a). As a result of the sharp salinity gradient across the ML base (colored contours in Fig. 10a), both of these processes will bring relatively salty water from below up into the ML. Notice that vertical advection has a larger relative effect on MLS than it does on MLT (Fig. 5c); this is due to the fact that the vertical temperature gradient near the ML base is much weaker throughout the year than the salinity gradient (e.g., compare Fig. 10a, b which show non-dimensionalized salinity and temperature, respectively).

Finally, horizontal advection is more important to MLS than to MLT, and it exhibits predominantly annual variability (Fig. 9b, fuchsia), largely accounting for the annual character of the net seasonal MLS tendency. This is partly a result of relatively sharper horizontal MLS gradients surrounding the region that can be linked to river run-off and differing water masses in the surrounding marginal seas and advection by the ITF currents of those water properties into the BandaArafura Seas on the timescale of the southeast-northwest monsoon winds. To demonstrate this, we show the mean June-September (JJAS) and December-March (DJFM) horizontal distributions of seasonal MLS anomaly and the climatological (seasonal plus time mean) ML current (Fig. 11) over the region. ${ }^{1}$ These maps illustrate the overall

\footnotetext{
${ }^{1}$ Note that all parameters in the budget equations can be expanded to show terms representing interactions between different timescales of variability, e.g., $\left[-\left(u \frac{\partial S}{\partial x}\right)^{*}=-\bar{u} \frac{\partial S^{*}}{\partial x}-u^{*} \frac{\partial \bar{S}}{\partial x}-u^{*} \frac{\partial S^{*}}{\partial x} ;-\left(v \frac{\partial S}{\partial y}\right)^{*}=\right.$ $\left.-\bar{v} \frac{\partial S^{*}}{\partial y}-v^{*} \frac{\partial \bar{S}}{\partial y}-v^{*} \frac{\partial S^{*}}{\partial y}\right]$ where bars denote time means and asterisks $(*)$ denote seasonal anomalies. Figure 11 panels indicate the combined effect of the advection of the seasonal MLS anomaly by the seasonal anomaly and time mean wind-driven ML currents, both of which affect the seasonal anomaly of the advective tendency. We then take the average over 4 months to show the general effect during the southeast (Fig. 11a) and northwest (Fig. 11b) monsoon seasons.
} 
(a)

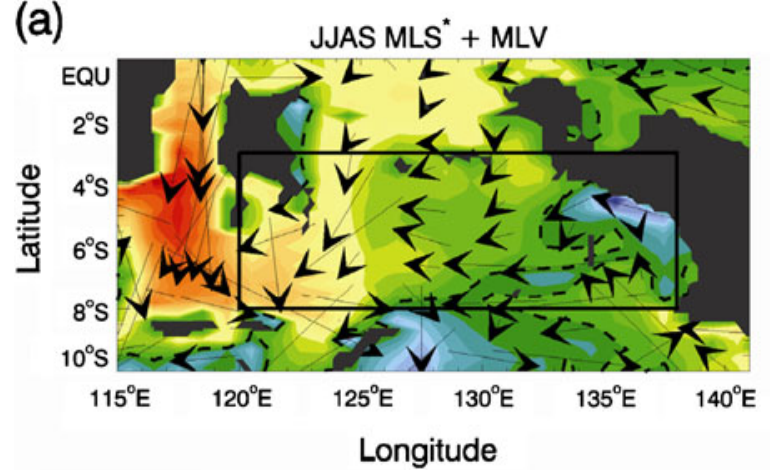

(b)

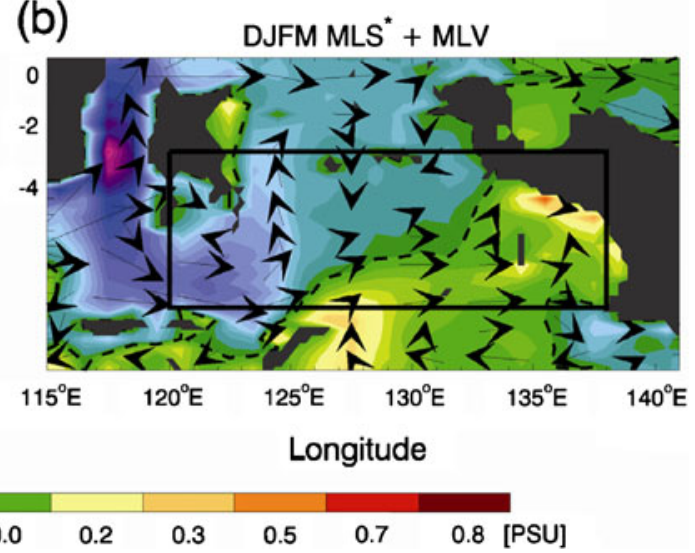

Fig. 11 MLS seasonal anomaly [in PSU] with climatological (seasonal plus time mean) ML current vectors $[\mathrm{m} / \mathrm{s}$ ] superimposed for a June through September $(J J A S)$ and b December through March $(D J F M)$. This plot indicates horizontal advection patterns of the seasonal
MLS anomaly by the seasonal and time mean currents (see footnote in "The seasonal MLS budget") associated largely with the southeasterly and northwesterly monsoon winds

salinity gradient near the ML base, advection of salinity across the base has a much larger relative effect on MLS than temperature advection has on MLT. The resultant horizontal gradient of MLT along the southeast corner of the box is thus smaller than the horizontal gradient of MLS

\section{Summary and conclusions}

Seasonal variability in the tropical ocean is often perceived as a "slave" response to atmospheric heat and freshwater forcing. This paper examines the seasonal MLT and MLS budgets in the Banda-Arafura Seas, a prime example of a climatically important region that is often simulated using a slab ocean model, even though ocean dynamics likely play important roles in the modulation of MLT and MLS here. MLT and MLS budgets are derived from an ECCO ocean-state estimate that conserves heat and salt, using density criteria to diagnostically determine time-varying MLH at each location. The effects of both surface forcing and ocean dynamics are addressed. Our results show that the seasonal variabilities of both MLT and MLS involve active ocean dynamics.

The largest contributor to seasonal MLT is surface heat flux, but there is a substantial secondary reinforcing contribution by turbulent vertical mixing in conjunction with the lifting of the pycnocline/upper thermocline in the Arafura Sea by monsoonal winds. The latter brings cooler subsurface water closer to the ML base, making it easier for turbulent vertical mixing to have a cooling effect. The MLT also has a small, but non-negligible, semi-annual component since insolation increases and surface winds weaken during the spring and fall monsoon transitions near the equator, causing surface heating, reduced surface heat loss, and reduced cooling by turbulent mixing. 
Seasonal MLS is dominated by horizontal advection and subsurface processes rather than by local freshwater fluxes. The contributions by horizontal advection and subsurface processes have comparable magnitudes and exhibit strong annual cycles, although subsurface processes also exhibit a small semiannual component.

In the case of both MLT and MLS, ocean processes are largely modulated by the monsoon winds, although remote thermocline forcing and complicated regional characteristics (e.g. bathymetry) may also play notable roles that require further investigation. Overall, the results presented above suggest that coupled model studies of climate in this region require a full (three-dimensional) ocean circulation model instead of a slab ocean ML model as the ocean model component. Our work can be used to evaluate the simulation of climate in this region by coupled models and to help interpret sparse in situ observations, from which complete budget analyses are difficult to derive.

Acknowledgement This research was carried out at the Jet Propulsion Laboratory, California Institute of Technology, under contract with NASA. Support by PO.DAAC (http://podaac.jpl.nasa.gov) is acknowledged. S. Kida was supported by KAKENHI (21840066).

Open Access This article is distributed under the terms of the Creative Commons Attribution Noncommercial License which permits any noncommercial use, distribution, and reproduction in any medium, provided the original author(s) and source are credited.

\section{References}

Ashok K, Guan Z, Yamagata T (2001) Impact of the Indian Ocean dipole on the decadal relationship between Indian monsoon rainfall and ENSO. Geo Res Let 28:4499-4502

Barnier B, Siefridt L, Marchesiello P (1995) Thermal forcing for a global ocean circulation model using a 3-year climatology of ECMWF analyses. J Mar Sys 6:363-380

Barsugli JJ, Sardeshmukh PD (2002) Global atmospheric sensitivity to tropical SST anomalies throughout the Indo-Pacific Basin. J Clim $15: 3427-3442$

Boyer TP, Levitus S (1998) Objective analysis of temperature and salinity for the world ocean on a $1 / 4^{\circ}$ grid. NOAA Atlas NESDIS $27,62 \mathrm{pp}$

da Silva AM, Young CC, Levitus S (1994) Atlas of marine surface data. US Gov Printing Office, Washington, DC, p 74pp

Ffield A, Robertson R (2008) Temperature finestructure in the Indonesian seas. J Geo Res 113:C09009. doi:10.1029/2006JC003864

Fukumori I (2002) A partitioned Kalman filter and smoother, Mo Wea. Rev 130:1370-1383

Gent PR, McWilliams JC (1990) Isopycnal mixing in ocean circulation models. J Phys Oceanogr 20:150-155

Gordon AL, Susanto RD (2001) Banda Sea surface-layer divergence. Oc Dyn 52:2-10

Gordon A, Susanto R, Ffield A, Huber B, Pranowo W, Wirasantosa S (2008) Makassar Strait throughflow 2004 to 2006. Geo Res Lett 35:L24605. doi:10.1029/2008GL036372

Halkides DJ, Lee T (2009) Mechanisms controlling seasonal-tointerannual mixed-layer temperature variability in the southeast tropical Indian Ocean. J Geophys Res 114:C02012. doi:10.1029/ 2008JC004949
Halkides DJ, Lee T (2011) Seasonal mixed layer temperature and salinity budgets along the southwestern tropical Indian Ocean thermocline ridge. (Accepted by Dynamics of Atmospheres and Oceans.)

Kalnay E, Kanamitsu M, Kistler R, et al. (1996) The NCEP/NCAR 40-year reanalysis project. Bull. Amer. Meteorol. Soc., 77, 437-471

Kelly KA, Qiu B (1995) Heat flux estimates for the North Atlantic. Part I: assimilation of satellite data into a mixed layer model. J Phys Oceanogr 25:2344-2360

Kessler WS, Rothstein LM, Chen D (1998) The annual cycle of SST in the eastern tropical Pacific, diagnosed in an ocean GCM*. J Climate 11:777-799. doi:10.1175/1520-0442(1998)011

Kida S, Richards KJ (2009) Seasonal sea surface temperature variability in the Indonesian seas. J Geophys Res 114:C06016. doi:10.1029/2008JC005150

Kim S-B, Lee T, Fukumori I (2004) The 1997-1999 abrupt change of the upper ocean temperature in the north central Pacific. Geophys Res Let 31(22):L22304

Kim S-B, Fukumori I, Lee T (2006) The closure of the ocean mixed layer temperature budget using level-coordinate model fields. J Ocean Atmos Tech 23(6):840-853

Kim S-B, Lee T, Fukumori I (2007) Mechanisms controlling the interannual variation of mixed layer temperature averaged over the NINO3 region. J Clim 20(15):3822-3843

Koch-Larrouy A, Madec G, Iudicone D, Atmadipoera A, Molcard R (2008) Physical processes contributing to the water mass transformation of the Indonesian throughflow. Ocean Dyn. doi:10.1007/s10236-008-0154-5

Large WG, McWilliams JC, Doney SC (1994) Ocean vertical mixing: a review and a model with a nonlocal boundary layer parameterization. Rev Geophys 32:363-404

Lee T, Fukumori I, Menemenlis D, Fu L-L (2002) Effects of the Indonesian throughflow on the Pacific and Indian Oceans. J Phys Oceanogr 32:1404-1429

Marshall JC, Hill C, Perelman L, Adcroft A (1997) Hydrostatic, quasihydrostatic and non-hydrostatic ocean modeling. J Geophys Res 102:5733-5752

McBride J, Haylock M, Nicholls N (2003) Relationships between the maritime continent heat source and the El Niño-southern oscillation phenomenon. J Clim 16:2905-2914

McPhaden MJ (2002) Mixed layer temperature balance on intraseasonal time scales in the equatorial Pacific Ocean. J Climate 15 (18):2632-2647

Miller M, Beljaars A, Palmer T (1992) The sensitivity of the ECMWF model to the parameterization of evaporation from the tropical oceans. J Climate 5:418-434

Monterey G, Levitus S (1997) Seasonal variability of mixed layer depth for the world ocean. NOAA Atlas NESDIS 14. US Gov. Printing Office, Washington, DC, $96 \mathrm{pp}, 87$ figs

Neale R, Slingo J (2003) The maritime continent and its role in the global climate: a GCM study. J Climate 16:834-848

Obata A, Ishizaka J, Endoh M (1996) Global verification of critical depth theory for phytoplankton bloom with climatological in situ temperature and satellite ocean color data. J Geophys Res 101 (C9):20657-20667. doi:10.1029/96JC 01734

Paulson CA, Simpson JJ (1977) Irradiance measurements in the upper ocean. J Phys Oceanogr 7:952-956

Price JF, Weller RA, Pinkel R (1986) Diurnal cycling: observations and models of the upper ocean response to diurnal heating, cooling, and wind mixing. J Geophys Res 91(C7):8411-8427. doi:10.1029/JC091iC07p08411

Qu T, Du Y, Strachan J, Meyers G, Slingo J (2005) Sea surface temperature and its variability in the Indonesian region. Oceanography 18 (4):50-61

Qu T, Gan J, Ishida A, Kashino Y, Tozuka T (2008) Semiannual variation in the western tropical Pacific Ocean. Geo Res Let 35: L16602. doi:10.1029/2008GL035058 
Reynolds R, Smith T, Liu C, Chelton D, Casey K, Schlax M (2007) Daily high-resolution-blended analyses for sea surface temperature. J Clim 20:5473-5496

Robertson R, Ffield A (2005) $\mathrm{M}_{2}$ baroclinic tides in the Indonesian seas. Oceanogr 18:62-73

Schiller A, Godfrey JS (2003) Indian Ocean intraseasonal variability in an ocean general circulation model. J Climate 16:21-39

Sprintall J, Liu WT (2005) Ekman mass and heat transport in the Indonesian seas. Oceanography 18:88-97
Wyrtki K (1961) Physical oceanography of the southeast Asian waters. University of California, NAGA Rept., No. 2, $195 \mathrm{pp}$

Wyrtki K (1962) The upwelling in the region between Java and Australia during the south-east monsoon. Aust J Mar Freshw Res 13:217-225

Wijffels SE, Meyers G (2004) An intersection of oceanic waveguides: variability in the Indonesian throughflow region. J Phys Oceanogr $34: 1,232-1,253$ 